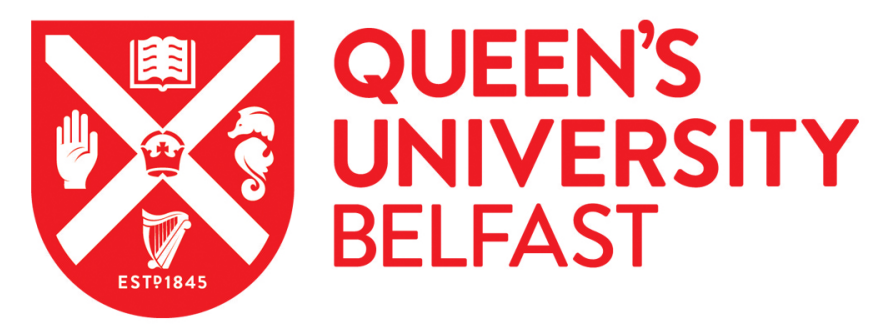

\title{
The effects of zinc supplementation on primary human retinal pigment epithelium
}

Pao, P-J., Emri, E., Abdirahman, S. B., Soorma, T., Zeng, H-H., Hauck, S. M., Thompson, R. B., \& Lengyel, I. (2018). The effects of zinc supplementation on primary human retinal pigment epithelium. Journal of trace elements in medicine and biology : organ of the Society for Minerals and Trace Elements (GMS). https://doi.org/10.1016/j.jtemb.2018.02.028

Published in:

Journal of trace elements in medicine and biology : organ of the Society for Minerals and Trace Elements (GMS)

Document Version:

Peer reviewed version

Queen's University Belfast - Research Portal:

Link to publication record in Queen's University Belfast Research Portal

Publisher rights

Copyright 2018 Elsevier

This manuscript is distributed under a Creative Commons Attribution-NonCommercial-NoDerivs License

(https://creativecommons.org/licenses/by-nc-nd/4.0/), which permits distribution and reproduction for non-commercial purposes, provided the author and source are cited.

\section{General rights}

Copyright for the publications made accessible via the Queen's University Belfast Research Portal is retained by the author(s) and / or other copyright owners and it is a condition of accessing these publications that users recognise and abide by the legal requirements associated with these rights.

Take down policy

The Research Portal is Queen's institutional repository that provides access to Queen's research output. Every effort has been made to ensure that content in the Research Portal does not infringe any person's rights, or applicable UK laws. If you discover content in the Research Portal that you believe breaches copyright or violates any law, please contact openaccess@qub.ac.uk. 
Title: The effects of zinc supplementation on primary human retinal pigment epithelium

Authors: Po-Jung Pao ${ }^{1,2}$, Eszter Emri ${ }^{1,4}$, Safiya Bishar Abdirahman ${ }^{1}$, Talha Soorma ${ }^{1}$, Hui-Hui Zeng ${ }^{5}$, Stefanie M. Hauck ${ }^{3}$, Richard B. Thompson ${ }^{5}$ and Imre Lengyel ${ }^{1,4}$

${ }^{1}$ Department of Ocular Biology and Therapeutics, UCL Institute of Ophthalmology, 11-43 Bath St, London EC1V 9EL, United Kingdom; ${ }^{2}$ Department of Structural and Molecular Biology, University College London, Gower Street, London, WC1E 6BT, United Kingdom; ${ }^{3}$ Research Unit Protein Science, Helmholtz Zentrum München, German Research Center for Environmental Health $(\mathrm{GmbH})$, Ingolstädter Landstraße 1, 85764 Oberschleißheim, Germany; ${ }^{4}$ Centre for Experimental Medicine, School of Medicine, Dentistry and Biomedical Sciences, Queen's University, 97 Lisburn Road, Belfast, BT9 7BL, Northern Ireland; ${ }^{5}$ Department of Biochemistry and Molecular Biology, University of Maryland School of Medicine, 108 N. Greene Street, Baltimore, MD 21201,United States

Po-Jung Pao: pojungpao@gmail.com, Eszter Emri: e.emri@qub.ac.uk, Safiya Bishar Abdirahman: $\quad$ safiya.bishar@hotmail.co.uk, Talha Soorma: talhasoorma@hotmail.com, Hui-Hui Zeng: hzeng001@yahoo.com, Stefanie M. Hauck: hauck@helmholtz-muenchen.de, Richard B. Thompson: RThompson@som.umaryland.edu, Imre Lengyel: 1.lengyel@qub.ac.uk

Short title: Zinc supplementation and the RPE

Corresponding author: Imre Lengyel, $\mathrm{PhD}$; Address: Centre for Experimental Medicine, School of Medicine, Dentistry and Biomedical Sciences, Queen's University, 97 Lisburn Road, Belfast, BT9 7BL, Northern Ireland; Tel: (+44) 028 9097 1643; Email: 1.lengyel@qub.ac.uk 


\section{ABSTRACT}

Population-based and interventional studies have shown that elevated zinc levels can reduce the progression to advanced age-related macular degeneration. The objective of this study was to assess whether elevated extracellular zinc has a direct effect on retinal pigment epithelial cells (RPE), by examining the phenotype and molecular characteristics of increased extracellular zinc on human primary RPE cells. Monolayers of human foetal primary RPE cells were grown on culture inserts and maintained in medium supplemented with increasing total concentrations of zinc $(0$, $75,100,125$ and $150 \mu \mathrm{M})$ for up to 4 weeks. Changes in cell viability and differentiation as well as expression and secretion of proteins were investigated. RPE cells developed a confluent monolayer with cobblestone morphology and transepithelial resistance (TER) $>200 \Omega * \mathrm{~cm}^{2}$ within 4 weeks. There was a zinc concentration-dependent increase in TER and pigmentation, with the largest effects being achieved by the addition of $125 \mu \mathrm{M}$ zinc to the culture medium, corresponding to $3.4 \mathrm{nM}$ available (free) zinc levels. The cells responded to addition of zinc by significantly increasing the expression of Retinoid Isomerohydrolase (RPE65) gene; cell pigmentation; Premelanosome Protein (PMEL17) immunoreactivity; and secretion of proteins including Apolipoprotein E (APOE), Complement Factor $\mathrm{H}$ (CFH), and High-Temperature Requirement A Serine Peptidase 1 (HTRA1) without an effect on cell viability. This study shows that elevated extracellular zinc levels have a significant and direct effect on differentiation and function of the RPE cells in culture, which may explain, at least in part, the positive effects seen in clinical settings. The results also highlight that determining and controlling of available, as opposed to total added, zinc will be essential to be able to compare results obtained in different laboratories.

Keywords: zinc, age related macular degeneration, retinal pigment epithelium, mass spectrometry 


\section{INTRODUCTION}

According to the population-based study conducted in Rotterdam, those with the highest quartile of zinc nutrition have a lower risk of progression in age-related macular degeneration (AMD) [1]. Decreased levels of total zinc in the peripheral blood serum and the retinal pigment epithelium (RPE)/choroid [2-6] have also been associated with development of AMD. Accordingly, the Age-Related Eye Disease Study (AREDS) trial showed that the progression to advanced AMD was significantly reduced in patients who received daily supplementation of $80 \mathrm{mg}$ zinc, especially in combination with a cocktail of antioxidants [7]. The mechanism behind this beneficial zinc effect remains elusive, but understanding the processes affected by zinc may lead to improved or novel treatment strategies for AMD.

Zinc is the second most abundant trace element in the human body [8-10]. Zinc toxicity is rarely observed in vivo $[11,12]$, although in cell culture experiments zinc overdose can trigger cell death [13-16]. In the eye, zinc is present in high concentrations [17-19] where the majority of ocular zinc is localised to the RPE/choroid complex [20]. Zinc deficiency or zinc overload in the RPE can lead to a variety of problems [21-25]. However, the actual concentration of biologically active or available zinc ions (e.g., the small fraction of total zinc ions not tightly bound by protein and other ligands) is not determined; therefore, comparison of results between laboratories is usually difficult. Active uptake and prolonged retention of zinc has been shown in RPE in vivo [26] and the presence of exchangeable zinc in RPE has been demonstrated [27, 28] and was localized to the Golgi apparatus [29], melanosomes, and lysosomes [30-33].

Based on protocols for culturing and differentiating human RPE cells [34-36] there are abundant high affinity zinc-binding proteins such as serum albumin in the culture medium and it is hypothesized that RPE cells in culture are in a potentially zincdeficient environment. In this report, we cultured primary human RPE cells in a zincenriched environment by supplementing the culture medium with different concentrations of added zinc sulphate and found that under these conditions $3.4 \mathrm{nM}$ free zinc could accelerate RPE differentiation, alter gene expression, and modify secretion of AMD-specific proteins. 


\section{MATERIALS AND METHODS}

\section{RPE Cell Culture.}

Primary human foetal RPE cells were purchased from ScienCell ${ }^{\mathrm{TM}}$ Research Laboratories at passage 1 (P1). Cells were propagated and frozen as P2 cells. For the experiments below, P3 cells were seeded onto laminin-coated 24 well plastic culture plates with glass cover slip or porous cell culture inserts (Millipore Millicell-HA Culture Plate Inserts, PIHA 01250) with the density of 125,000 cells per square centimetre and cultured in Epithelial Cell Medium (EpiCM, ScienCell ${ }^{\mathrm{TM}}$ Research Laboratories) for one week to allow optimal propagation, following the manufacturer's instructions. Following this period cells were differentiated in the socalled "Miller medium"[35] with or without 75, 100, 125, 150 or $200 \mu \mathrm{M}$ added zinc sulphate (Sigma-Aldrich) apically, and when the cell culture insert was used, nonsupplemented medium basally for 28 days. Medium was changed twice a week and cells were maintained at $37^{\circ} \mathrm{C}$ and $5 \% \mathrm{CO}_{2}$. Prior to change of culture medium, transepithelial resistance (TER) was measured using the EVOM2 Epithelial Voltohmmeter and STX2 electrodes (World Precision Instruments). Both apical and basal media were collected at the time of the change of medium for toxicity measurements using the CytoTox 96® Non-Radioactive Cytotoxicity Assay (Promega) to monitor cell viability. Pigmentation was imaged using a Nikon LZM1500 binocular microscope at 1x magnification and the coverage of pigment at different zinc concentrations was determined by ImageJ software (ImageJ v.1.51p; background subtraction and thresholding then analysing particle size distribution).

\section{Determination of free zinc in the medium}

Zinc concentrations in the Miller medium were calculated using MINEQL, a chemical equilibrium program for personal computers [37],as well as measured using fluorescent sensors essentially as described [13]. Briefly, the known affinities [23, 38] and concentrations of the 25 most important zinc ligands were included in the calculation; other potential ligands (e.g. vitamins, growth factors) were not included in the calculation due to their low concentrations $(<10 \mathrm{nM})$ and/or weak affinities $\left(\mathrm{K}_{\mathrm{D}}>1 \mu \mathrm{M}\right)$. Bioavailable ("free") zinc was held to include $\mathrm{Zn}^{2+}$ together with its labile complexes with weak, rapidly exchangeable ligands such as water, hydroxide, or chloride: e.g., $\mathrm{ZnOHCl}, \mathrm{ZnCl}_{2}$, etc. The results were corrected for temperature, 
ionic strength, and $\mathrm{pH}$, and the presence of dissolved $\mathrm{CO}_{2}$ in the medium was included. The accuracy of this calculation method was previously demonstrated for other media[39] and sea water[40]. We used a variation on our previously described fluorescence-based zinc biosensors [41-43] to measure the free zinc in the growth medium. The sensor employed one of two variants of apocarbonic anhydrase II to provide sensitivity to the appropriate free zinc concentrations, and a polymeric form of ABDN (7-amino-(2'-hydroxyethyl)-benz-2-oxa-1,3-diazole-4-sulfonamide) which exhibits a $50 \mathrm{~nm}$ blue shift in its peak fluorescence emission when bound to holocarbonic anhydrase compared to its unbound form which is observed in the absence of zinc, when both are entrapped in a porous gel. The ratio of fluorescence emission at 550 to $600 \mathrm{~nm}$ is thus a measure of the proportion of carbonic anhydrase with zinc bound, which in turn is a simple function of the free zinc concentration[41]. The variants of the carbonic anhydrase were wild type bovine CA II and H94N human CA II, which exhibited apparent $\mathrm{K}_{\mathrm{D}}$ 's under the conditions of the experiment of $0.10 \pm 0.033$ and $0.71 \pm 0.06 \mathrm{nM}$, respectively (data not shown).

\section{Immunohistochemistry (IHC) and confocal microscopy}

After 28 days of zinc supplementation, specimens were rinsed in PBS $(3 \times 5 \mathrm{~min})$, fixed for $10 \mathrm{~min}$ in $4 \%(\mathrm{v} / \mathrm{v})$ paraformaldehyde in PBS, and stored in $0.4 \%$ paraformaldehyde pending sectioning and immunohistochemical analysis. The membrane inserts were carefully excised, then cryopreserved by immersion in $30 \%$ $(\mathrm{w} / \mathrm{v})$ sucrose (in PBS) overnight at $4^{\circ} \mathrm{C}$, followed by $30 \%$ sucrose plus Tissue-Tek ${ }^{\circledR}$ O.C.T. ${ }^{\text {тм }}$ compound (Sakura) at 50\%:50\% (vol:vol) for $2 \mathrm{hr}$, and finally in 100\% (v/v) O.C.T. for $1 \mathrm{hr}$. Cryopreserved samples were embedded in OCT and $20 \mu \mathrm{m}$ sections were generated on a cryostat (Bright Instruments). Sections were rinsed with PBS and blocked with 5\% (v/v) donkey serum in PBT (PBT: PBS containing 0.5\% $(\mathrm{w} / \mathrm{v})$ bovine serum albumin and $0.1 \%(\mathrm{v} / \mathrm{v})$ Triton $\mathrm{X}-100)$ for $1 \mathrm{hr}$ at room temperature. The sections were co-labelled with polyclonal goat anti-human Apolipoprotein E (1/500 in PBT, Millipore) and monoclonal mouse anti-human PMEL17 (clone HMB45, 1/2000 in PBT, Dako) antibodies for $1 \mathrm{hr}$ at room temperature. Sections were rinsed for $3 \times 5 \mathrm{~min}$ in PBS, after which they were incubated in Alexa Fluor 546-conjugated donkey anti-goat IgG and Alexa Fluor 488conjugated donkey anti-mouse IgG (both $1 / 200$ in PBT, Life Technologies) for $1 \mathrm{hr}$ at 
room temperature. After removal of the secondary antibodies by rinsing the sections with $3 \times 5$ min in PBS, nuclei were stained with Hoechst $33342(1.5 \mu \mathrm{g} / \mathrm{ml}$ in PBS, Life Technologies) and mounted on slides with Vectashield antifade mounting medium (Vector Laboratories). Immunofluorescence was imaged using a Zeiss LSM700 confocal microscope and analysed by ZEN 2 software (Carl Zeiss Microscopy $\mathrm{GmbH})$.

\section{Transmission electron microscopy (TEM)}

After 28 days of zinc supplementation, specimens for TEM were fixed in a solution of $1 \%(\mathrm{v} / \mathrm{v})$ glutaraldehyde and $1.5 \%(\mathrm{v} / \mathrm{v})$ paraformaldehyde in $0.1 \mathrm{M}$ PBS at $\mathrm{pH}$ 7.2. Specimens were post-fixed with $1 \%(\mathrm{w} / \mathrm{v})$ osmium tetroxide in $0.1 \mathrm{M}$ PBS for $50 \mathrm{~min}$, dehydrated and embedded in Araldite. For EM, ultra-thin sections were cut and stained with $1 \%(\mathrm{w} / \mathrm{v})$ uranyl acetate and Reynolds' lead citrate. Semi-thin sections for light microscopy were also cut and stained with Toluidine Blue. EM was performed using a JEOL JEM-1010 Transmission Electron Microscope. Images were collected using a Gatan Orius CCD camera and converted from Digital Micrograph DM3 format to 8-bit TIFF images for analysis at 4008 X 2762-pixel resolution.

\section{Mass spectrometry and label-free quantitative analysis}

To analyse the secreted proteins with or without $125 \mu \mathrm{M}$ added zinc at day 28 after zinc supplementation, cells were washed with $1 \times 5$ min PBS then kept in serum-free "Miller medium" for $24 \mathrm{hr}$, after which the apical secretome and the filter insert for basal secretion were collected and frozen immediately, except when part of the membrane insert was fixed for immunolabeling. Proteins absorbed by the membrane during culturing representing the basally secreted protein pool were directly proteolyzed on the membrane by incubation with ammonium bicarbonate buffer, reduction with dithiothreitol for 30 minutes at $60^{\circ} \mathrm{C}$, followed by carbamidomethylation of cysteines with iodacetamide for 30 minutes at room temperature under constant agitation. Proteins contained in the apical secreted compartment were digested by a filter-aided sample preparation method as described previously [44]. Trypsin $(1 \mu \mathrm{g})$ was added and samples were digested overnight at $37^{\circ} \mathrm{C}$. Peptides were acidified and directly used for mass spectrometry.

LC-MS/MS analysis was performed on an Orbitrap XL mass spectrometer (ThermoFisher Scientific) online coupled to an Ultimate 3000 RSLC nano-HPLC 
(Dionex) as described [44]. Acquired raw data was loaded onto the Progenesis QI software for MS intensity-based label-free quantification (Nonlinear Dynamics, Waters). After alignment to achieve a maximum overlay of peptide features, filtering of singly charged features and features with charges $>7$ as well as normalization to correct for systematic experimental variation, all MSMS spectra were exported and searched against the Ensembl human database (100158 sequences) using the Mascot search engine with the following search settings: enzyme trypsin, one missed cleavage allowed; $10 \mathrm{ppm}$ peptide mass tolerance and 0.6 Da fragment mass tolerance. Carbamidomethylation was set as fixed modification, methionine oxidation and asparagine or glutamine deamidation were allowed as variable modifications. A Mascot-integrated decoy database search calculated an average false discovery of $<0.1 \%$ when searches were performed with a mascot percolator score cut-off of 18 and significance threshold of 0.01 . Peptide assignments were re-imported into the Progenesis QI software. The abundances of all unique peptides allocated to each protein were summed up and the resulting normalized abundances were used for calculation of fold-changes of proteins and significance values by a Student's T-test.

\section{RESULTS}

\section{Determination of free zinc concentrations in the Miller medium}

While publications usually report only the added zinc concentration to an experiment, the concentration of added (or total) zinc is typically much greater than that readily available for biological activity. Most of the added zinc is tightly bound to proteins, amino acids and other components of the culture medium. Thus, the concentration of zinc that cells will actually be exposed to depends critically on the composition of a culture medium [13] and therefore, the level of free, rapidly exchangeable zinc was modelled in the RPE culturing "Miller" medium, used for our zinc supplementation. With the known amounts and zinc affinities of the principal components of the medium, free zinc levels were calculated and measured to be at least one thousandfold lower (in the nM range) than the total levels present in the medium (Figure 1). Comparable results had been obtained with other media and cells or cell lines previously [39]. Also, our model was validated by measuring the free zinc as a function of added zinc in the medium with two different fluorescence sensors (Figure 1); the good agreement between measured and calculated levels of available zinc in 
this and other media suggests that MINEQL accurately predicts the level of available zinc present for a given level of added (total) zinc. Henceforward, the zinc effects are also reported in terms of the free zinc concentration.

The effects of zinc on the differentiation and maturation of RPE cells: Development of transepithelial resistance (TER)

RPE cells in vivo are highly differentiated both morphologically and functionally. One indicator of RPE cell differentiation is the development of TER. In the absence of added zinc (Figure 2, the maximum TER value after 4 weeks in culture was $208.6 \Omega * \mathrm{~cm}^{2}$. Cells cultured with $75 \mu \mathrm{M}$-added zinc (2.0 $\mathrm{nM}$ free zinc) showed no effect on TER compared with no added zinc. However, both $100 \mu \mathrm{M}$ and $125 \mu \mathrm{M}$ added zinc (2.7 $\mathrm{nM}$ and $3.4 \mathrm{nM}$ free zinc, respectively) produced a robust and statistically significant increase in the TER which plateaued at $343.2 \Omega * \mathrm{~cm}^{2}$. Addition of $150 \mu \mathrm{M}$ zinc (4.0 $\mathrm{nM}$ free zinc) produced no change in TER at any of the time points compared with no added zinc. None of these concentrations of added zinc was toxic to the RPE cells as no change in LDH release was detected (Figure S1). However, addition of $200 \mu \mathrm{M}$ zinc resulted in round-shaped RPE cells and detachment from the insert membrane. Based on the results of the TER measurement in subsequent experiments we used $125 \mu \mathrm{M}$ added zinc, equivalent to $3.4 \mathrm{nM}$ free zinc.

\section{Pigmentation}

Well-differentiated RPE cells develop pigmentation, basally located nuclei, and numerous apical microvilli[36]. Pigmentation was visualized by light microscopy (Figure 3) and quantified at the end of 28 days of zinc supplementation. Both controls and zinc-treated samples exhibited pigments, however in the presence of zinc the extent of pigmentation was much more widespread (Figure $3 \mathrm{~A}$ and $\mathrm{D}$, respectively). In our hand, in the absence of zinc, pigmentation appeared first close to the edge of the inserts (Figure 3A). Our observations were validated qualitatively by comparing TEM images from 0 and $125 \mu \mathrm{M}$ added zinc. We found higher numbers of pigment granules and apical microvilli in the presence of $125 \mu \mathrm{M}$ added zinc (Figure 3B and E). Immunolabeling with anti-PMEL17, which labels pre-melanosomes, showed increased immunoreactivity after zinc treatment, supporting the EM observations (Figure 3C and F, respectively). The increase in pigmentation was assessed 
quantitatively by analysing the level of pigmentation at different concentrations of added zinc (Figure 3G).

\section{Basal and apical secretion of proteins}

Polarised RPE cells have been shown to secrete a variety of proteins both apically and basally [45]. Apolipoprotein E (APOE) had been used to monitor basal secretion and sub-RPE accumulation of materials [46]. The immunoreactivity of this protein was therefore used to examine the effects of zinc in basal secretion in our experiments. As expected, APOE accumulated in the cell culture inserts (Fig 3C, magenta) in a fashion identical to that reported by Johnson et al.[46]. In the presence of $125 \mu \mathrm{M}$ added zinc we detected an increase in APOE immunoreactivity in the filter inserts (Figure 3F; magenta). This qualitative observation was then confirmed by MS analysis (Table 1) in which a significant increase in secretion of APOE and other proteins was detected upon zinc treatment in membrane inserts (Table 1). While most changes in protein levels increased after zinc treatment, Histone cluster 1, H2ae secretion showed a significant decrease (Table 1 and Supplementary table T1).

We also examined the effects of zinc supplementation on protein secretion in the apical compartment of the RPE (Table 2 and Supplementary table T2). There were several proteins that showed increased secretion after zinc supplementation in the apical compartment (Table 2). Particularly interesting were the increased secretion of complement factor $\mathrm{H}(\mathrm{CFH})$ [47-49] and high temperature requirement serine protease A1 (HTRA1) [50, 51] which are genetically associated with AMD [52-55]. 


\section{DISCUSSION}

An outstanding question in relation to AMD is how zinc supplementation exerts its observed beneficial effect [56-59]. Here we report that one of the ways is through direct effects on the RPE cells. Our results suggest that the availability of zinc can directly and significantly affect the RPE, and therefore may have influence on the interactions of the RPE with the photoreceptors and the choroidal micro vessels.

Zinc is indispensable for a multitude of molecular functions including, but not restricted to, regulating transcription factors, hundreds of enzyme activities, and protein structure and stability, as well as signaling [60]. Experiments with other tissues showed that zinc is involved in maintaining membrane integrity and tight junction formation [61-65]. In fact, zinc supplementation had a direct effect on zona ocludens-1 and occludin [66], which are both present and part of tight junctions in RPE cells; this may explain the significant change in TER in our experiments (Figure 2). In addition, zinc may affect the cytoskeletal network [67] and thereby exert its effect or contribute to changes in TER through the reorganization of the cytoskeleton. One of the important functions of RPE cells is to regulate the transport in and out of the neural retina. Therefore, regulation of TER by zinc will have important consequences in vivo as the RPE monolayer is part of the outer blood-retinal barrier.

Pigmentation is used as a differentiation marker for RPE cells [68, 69]. Melanin is thought to play a role in both normal and pathological behavior of RPE cells [70]. Melanin production is a complex process directly involving three enzymes: tyrosinase and tyrosinase-related proteins 1 (TYRP1) and 2 (TYRP2). Zinc directly binds to tyrosinase and TYRP2 [71-74], which could be the reason for the high zinc content of melanosomes [75-77]. In addition, zinc directly affects the activities of tyrosinase and TYRP2, which may explain why the zinc-enriched environment increased the cell pigmentation, leading to increased immunoreactivity of PMEL17 in our experiments (Figure 3). The increased melanin content and TER values were accompanied by increased density of apical microvilli and melanosomes (Figure $3 \mathrm{~B}$ and E), all of which are characteristic of RPE cell maturation [34-36, 78]. Therefore, increased availability of zinc appears to be directly involved in the development and probably maintenance of a mature and healthy RPE. 
RPE cells transport and secrete a variety of proteins, lipids and other chemicals bidirectionally $[45,79-81]$ and there is an apical/basal difference in this process in vivo as well as in cell culture [45]. Perhaps not surprisingly, we identified several proteins in the apical and basal secretome (Supplementary table 1 and 2). Amongst the basally secreted proteins was APOE, which has been associated with AMD [82], and had been shown to be secreted from and accumulated under primary human RPE cells in culture $[46,83]$. We not only found that APOE behaves the same way in our experiments, but also showed that zinc increases the secretion of this protein (Table 1 and Figure 3). The association between APOE and zinc appears to be at multiple levels. APOE isoforms bind zinc directly [84], and this binding can increase their stability [85]. In addition, it is believed that zinc can increase cellular APOE levels by directly affecting transcription [86] and/or secretion [87]. Which of these lead to the increased accumulation of APOE in our experiments will need to be investigated further, especially in light of the involvement of APOE in sub-RPE deposit formation [88]. Apart from APOE we identified a number of other components of sub-RPE deposits [89] in the basal secretome (Supplementary table T1) and some of these were significantly affected by the addition of extracellular zinc (Table1). Apart from changes in basal secretion, apical secretion was also affected by zinc supplementation (Table 2). We found increases in secretion of CFH and HTRA1, both of which have been previously reported in RPE secretomes $[54,55]$. The exact role of these apically secreted proteins is yet to be determined, but it was suggested that both might protect photoreceptors from effects of inappropriate complement activation and/or amyloid deposition $[54,55]$.

Previously we reported that on thin polycarbonate inserts sub-RPE deposits can readily form drusen-like deposits [83]. We did not see such deposits in this study. This might be due to the use of $100 \mu \mathrm{m}$ thick mixed cellulose esters in the inserts, into which proteins can diffuse and become trapped in the fiber meshwork. Entrapment within the insert was observed in another study [46], suggesting that this type of filter insert is useful to analyze the basal secretome.

The concentration of total zinc that was added to the cell culture medium in our experiments was several orders of magnitude higher than the resulting free or bioavailable zinc concentration that is available for biological functions (125 $\mu \mathrm{M}$ vs 
$3.4 \mathrm{nM}$, respectively). This is routinely seen due to the complex mixtures containing many zinc buffering components in the culture medium [13]. For example, fetal bovine serum, comprised of a mixture of serum albumin, amino acids, growth factors, protease inhibitors, proteins, lipids, and minerals [90], has both a large zinc-binding capacity and affinity: albumin and alpha-2-macroglobulin together bind more than $98 \%$ of serum zinc [91-93]. As a result, only a small fraction of zinc in serum is really available to be biologically active [13]. For this very reason, if cells would release zinc this zinc would be rapidly captured by the buffers and would not affect biological activity. Thus, the free zinc concentration is effectively "clamped" in these experiments.

Different cell lines require different culture media, therefore it is important to report not only the added zinc but also the resulting bioavailable zinc concentrations [13]. It is also important to note that based on previous work by Bozym, et al. [13, 39], the effects in terms of free zinc are transferrable to other systems and media whereas the effects of added zinc are not. While this might not be true for all media, MINEQL calculation of zinc accurately reflected the measured available zinc levels in our experiment (Figure 1.). Based on this, we also calculated the buffering capacity of DMEM/F12, another medium often used to culture RPE cells, and found that one can reach $\sim 3 \mathrm{nM}$ free zinc at the concentration of $<40 \mu \mathrm{M}$ added zinc, a three to four-fold lowered buffering capacity compared to the Miller medium used in this report. While direct determination is always preferred, it appears that modelling buffering capacity can give a good estimate for potential biological activity.

In summary, increased zinc availability had a multitude of effects on the RPE cells in our experiments. In addition to our findings, zinc has been shown to mediate oxidative stress[94], phagocytic and lysosomal function [70, 95], macromolecule synthesis- and caspase-dependent apoptosis[96], increased photic injury [97], and DNA damage[98]. Zinc can also kill RPE cells in culture if there is too much or too little of it [25, 96], although in vivo toxicity is rarely reported [11, 12]. Interestingly, the range of free zinc concentrations that RPE cells are able to handle appears to be relatively narrow, $<5 \mathrm{nM}$, at least in culture. It is unclear whether in vivo the extracellular milieu has bioavailable zinc identical or similar to these values. However, the fact that culture media have a capacity to keep available zinc levels in 
our experiments in the nanomolar range even up to $150 \mu \mathrm{M}$ added zinc suggests that zinc buffering capacity will need to be considered when in vitro and in vivo supplementations are considered. The challenge now is to determine the "normal" free zinc concentration for the RPE in vivo. The RPE directly interacts with the photoreceptors and the Bruch's membrane, and indirectly with the choroidal circulation. Given that total zinc levels are altered in human eyes with signs of AMD [6,99-101], all the reported changes suggest that determining and maintaining a "healthy" concentration of available zinc will be important for the maturation and health of the RPE, therefore intervening the development and progression of AMD.

Acknowledgments: The authors thank Professor Alan C. Bird for helpful discussions and Andrea Stoddard and Carol Fierke of the University of Michigan for the carbonic anhydrase variants. The research was supported by the Bill Brown Charitable Trust Senior Research Fellowship, Moorfields Eye Hospital Special Trustees, and the Mercer Fund from Fight for Sight (I.L) and the Bright Focus Foundation (R.B.T. and I.L.). This work was supported by STSM grants from COST Action TD-1304, the Network for the Biology of Zinc (Zinc-Net) (E.E). This project has received funding from the European Union's Horizon 2020 research and innovation programme under grant agreement No 634479 for the "Eye-Risk" project.

Competing interests: The authors declare that they have no competing interests. 


\section{REFERENCES}

[1] L. Ho, R. van Leeuwen, J.C. Witteman, C.M. van Duijn, A.G. Uitterlinden, A. Hofman, P.T. de Jong, J.R. Vingerling, C.C. Klaver, Reducing the genetic risk of agerelated macular degeneration with dietary antioxidants, zinc, and omega-3 fatty acids: the Rotterdam study, Arch Ophthalmol 129(6) (2011) 758-66.

[2] J.C. Erie, J.A. Good, J.A. Butz, J.S. Pulido, Reduced zinc and copper in the retinal pigment epithelium and choroid in age-related macular degeneration, Am $\mathrm{J}$ Ophthalmol 147(2) (2009) 276-282 e1.

[3] K.W. Leung, A. Gvritishvili, Y. Liu, J. Tombran-Tink, ZIP2 and ZIP4 mediate agerelated zinc fluxes across the retinal pigment epithelium, J Mol Neurosci 46(1) (2012) 122-37.

[4] D.J. Tate, Jr., P.D. Oliver, M.V. Miceli, R. Stern, S. Shuster, D.A. Newsome, Agedependent change in the hyaluronic acid content of the human chorioretinal complex, Arch Ophthalmol 111(7) (1993) 963-7.

[5] N.K. Wills, V.M. Ramanujam, N. Kalariya, J.R. Lewis, F.J. van Kuijk, Copper and zinc distribution in the human retina: relationship to cadmium accumulation, age, and gender, Exp Eye Res 87(2) (2008) 80-8.

[6] D.A. Newsome, M.V. Miceli, D.J. Tate, N.W. Alcock, P.D. Oliver, Zinc content of human retinal pigment epithelium decreases with age and macular degeneration, but superoxide dismutase activity increases, The Journal of Trace Elements in Experimental Medicine 8(4) (1996) 193-199.

[7] A.-R.E.D.S.R. Group, A randomized, placebo-controlled, clinical trial of high-dose supplementation with vitamins $\mathrm{C}$ and $\mathrm{E}$, beta carotene, and zinc for age-related macular degeneration and vision loss: AREDS report no. 8, Arch Ophthalmol 119(10) (2001) 1417-36.

[8] M. Stefanidou, C. Maravelias, A. Dona, C. Spiliopoulou, Zinc: a multipurpose trace element, Arch Toxicol 80(1) (2006) 1-9.

[9] M. Murakami, T. Hirano, Intracellular zinc homeostasis and zinc signaling, Cancer Sci 99(8) (2008) 1515-22.

[10] W. Maret, Zinc and human disease, Met Ions Life Sci 13 (2013) 389-414.

[11] L.M. Plum, L. Rink, H. Haase, The essential toxin: impact of zinc on human health, Int J Environ Res Public Health 7(4) (2010) 1342-65.

[12] G.J. Fosmire, Zinc toxicity, Am J Clin Nutr 51(2) (1990) 225-7.

[13] R.A. Bozym, F. Chimienti, L.J. Giblin, G.W. Gross, I. Korichneva, Y. Li, S. Libert, W. Maret, M. Parviz, C.J. Frederickson, R.B. Thompson, Free zinc ions outside a narrow concentration range are toxic to a variety of cells in vitro, Exp Biol Med (Maywood) 235(6) (2010) 741-50.

[14] M. Yokoyama, J. Koh, D.W. Choi, Brief exposure to zinc is toxic to cortical neurons, Neurosci Lett 71(3) (1986) 351-5.

[15] J.H. Weiss, D.M. Hartley, J.Y. Koh, D.W. Choi, AMPA receptor activation potentiates zinc neurotoxicity, Neuron 10(1) (1993) 43-9.

[16] W.G. Telford, P.J. Fraker, Preferential induction of apoptosis in mouse CD4+CD8+ alpha beta TCRloCD3 epsilon lo thymocytes by zinc, J Cell Physiol 164(2) (1995) 259-70.

[17] Z.A. Karcioglu, Zinc in the eye, Surv Ophthalmol 27(2) (1982) 114-22.

[18] B.H. Grahn, P.G. Paterson, K.T. Gottschall-Pass, Z. Zhang, Zinc and the eye, J Am Coll Nutr 20(2 Suppl) (2001) 106-18.

[19] M.A. Galin, H.D. Nano, T. Hall, Ocular zinc concentration, Invest Ophthalmol 1 (1962) 142-8. 
[20] M. Ugarte, N.N. Osborne, L.A. Brown, P.N. Bishop, Iron, zinc, and copper in retinal physiology and disease, Surv Ophthalmol 58(6) (2013) 585-609.

[21] D.J. Tate, M.V. Miceli, D.A. Newsome, N.W. Alcock, P.D. Oliver, Influence of zinc on selected cellular functions of cultured human retinal pigment epithelium, Curr Eye Res 14(10) (1995) 897-903.

[22] D.J. Tate, Jr., M.V. Miceli, D.A. Newsome, Zinc induces catalase expression in cultured fetal human retinal pigment epithelial cells, Curr Eye Res 16(10) (1997) 1017-23.

[23] D.J. Tate, Jr., M.V. Miceli, D.A. Newsome, Zinc protects against oxidative damage in cultured human retinal pigment epithelial cells, Free Radic Biol Med 26(56) (1999) 704-13.

[24] N.N. Osborne, J.P. Wood, The beta-adrenergic receptor antagonist metipranolol blunts zinc-induced photoreceptor and RPE apoptosis, Invest Ophthalmol Vis Sci 47(7) (2006) 3178-86.

[25] J. Song, S.C. Lee, S.S. Kim, H.J. Koh, O.W. Kwon, J.J. Kang, E.K. Kim, S.H. Shin, J.H. Lee, Zn2+-induced cell death is mediated by the induction of intracellular ROS in ARPE-19 cells, Curr Eye Res 28(3) (2004) 195-201.

[26] D.A. Newsome, P.D. Oliver, D.M. Deupree, M.V. Miceli, J.G. Diamond, Zinc uptake by primate retinal pigment epithelium and choroid, Curr Eye Res 11(3) (1992) 213-7.

[27] M. Ugarte, N.N. Osborne, The localization of endogenous zinc and the in vitro effect of exogenous zinc on the GABA immunoreactivity and formation of reactive oxygen species in the retina, Gen Pharmacol 30(3) (1998) 297-303.

[28] X. Wang, Z.Y. Wang, H.L. Gao, G. Danscher, L. Huang, Localization of ZnT7 and zinc ions in mouse retina--immunohistochemistry and selenium autometallography, Brain Res Bull 71(1-3) (2006) 91-6.

[29] T. Akagi, M. Kaneda, K. Ishii, T. Hashikawa, Differential subcellular localization of zinc in the rat retina, J Histochem Cytochem 49(1) (2001) 87-96.

[30] R.J. Ulshafer, Zinc content in melanosomes of degenerating RPE as measured by X-ray mapping, Prog Clin Biol Res 314 (1989) 131-9.

[31] R.J. Ulshafer, C.B. Allen, M.L. Rubin, Distributions of elements in the human retinal pigment epithelium, Arch Ophthalmol 108(1) (1990) 113-7.

[32] T.L. van der Schaft, W.C. de Bruijn, C.M. Mooy, D.A. Ketelaars, P.T. de Jong, Element analysis of the early stages of age-related macular degeneration, Arch Ophthalmol 110(3) (1992) 389-94.

[33] M. Ugarte, N.N. Osborne, Zinc in the retina, Prog Neurobiol 64(3) (2001) 21949.

[34] J. Hu, D. Bok, A cell culture medium that supports the differentiation of human retinal pigment epithelium into functionally polarized monolayers, Mol Vis 7 (2001) 14-9.

[35] A. Maminishkis, S. Chen, S. Jalickee, T. Banzon, G. Shi, F.E. Wang, T. Ehalt, J.A. Hammer, S.S. Miller, Confluent monolayers of cultured human fetal retinal pigment epithelium exhibit morphology and physiology of native tissue, Invest Ophthalmol Vis Sci 47(8) (2006) 3612-24.

[36] S. Sonoda, C. Spee, E. Barron, S.J. Ryan, R. Kannan, D.R. Hinton, A protocol for the culture and differentiation of highly polarized human retinal pigment epithelial cells, Nat Protoc 4(5) (2009) 662-73.

[37] M. Pons, M.E. Marin-Castano, Cigarette smoke-related hydroquinone dysregulates MCP-1, VEGF and PEDF expression in retinal pigment epithelium in vitro and in vivo, PLoS One 6(2) (2011) e16722. 
[38] A.E. Martell, R.M. Smith, Critical stability constants, (1977).

[39] R. Bozym, T.K. Hurst, N. Westerberg, A. Stoddard, C.A. Fierke, C.J. Frederickson, R.B. Thompson, Determination of zinc using carbonic anhydrase-based fluorescence biosensors, Methods Enzymol, United States, 2008, pp. 287-309.

[40] H.H. Zeng, R.B. Thompson, B.P. Maliwal, G.R. Fones, J.W. Moffett, C.A. Fierke, Real-time determination of picomolar free $\mathrm{Cu}(\mathrm{II})$ in seawater using a fluorescence-based fiber optic biosensor, Anal Chem 75(24) (2003) 6807-12.

[41] R.B. Thompson, W.O.W. Jr., B.P. Maliwal, C.A. Fierke, C.J. Frederickson, Fluorescence microscopy of stimulated $\mathrm{Zn}$ (II) release from organotypic cultures of mammalian hippocampus using a carbonic anhydrase-based biosensor system, Journal of Neuroscience Methods 96(1) (2000) 35 - 45.

[42] C.A. Fierke, R.B. Thompson, Fluorescence-based biosensing of zinc using carbonic anhydrase, Biometals 14(3-4) (2001) 205-22.

[43] T.K. Hurst, D. Wang, R.B. Thompson, C.A. Fierke, Carbonic anhydrase II-based metal ion sensing: Advances and new perspectives, Biochimica et Biophysica Acta (BBA) - Proteins \& Proteomics 1804(2) (2010) 393 - 403.

[44] A. Grosche, A. Hauser, M.F. Lepper, R. Mayo, C. von Toerne, J. Merl-Pham, S.M. Hauck, The Proteome of Native Adult Muller Glial Cells From Murine Retina, Mol Cell Proteomics 15(2) (2016) 462-80.

[45] P. Kay, Y.C. Yang, L. Paraoan, Directional protein secretion by the retinal pigment epithelium: roles in retinal health and the development of age-related macular degeneration, J Cell Mol Med 17(7) (2013) 833-43.

[46] L.V. Johnson, D.L. Forest, C.D. Banna, C.M. Radeke, M.A. Maloney, J. Hu, C.N. Spencer, A.M. Walker, M.S. Tsie, D. Bok, M.J. Radeke, D.H. Anderson, Cell culture model that mimics drusen formation and triggers complement activation associated with age-related macular degeneration, Proc Natl Acad Sci U S A 108(45) (2011) 18277-82.

[47] R.J. Klein, C. Zeiss, E.Y. Chew, J.Y. Tsai, R.S. Sackler, C. Haynes, A.K. Henning, J.P. SanGiovanni, S.M. Mane, S.T. Mayne, M.B. Bracken, F.L. Ferris, J. Ott, C. Barnstable, J. Hoh, Complement factor H polymorphism in age-related macular degeneration, Science 308(5720) (2005) 385-9.

[48] A.O. Edwards, R. Ritter, 3rd, K.J. Abel, A. Manning, C. Panhuysen, L.A. Farrer, Complement factor $\mathrm{H}$ polymorphism and age-related macular degeneration, Science 308(5720) (2005) 421-4.

[49] J.L. Haines, M.A. Hauser, S. Schmidt, W.K. Scott, L.M. Olson, P. Gallins, K.L. Spencer, S.Y. Kwan, M. Noureddine, J.R. Gilbert, N. Schnetz-Boutaud, A. Agarwal, E.A. Postel, M.A. Pericak-Vance, Complement factor $\mathrm{H}$ variant increases the risk of age-related macular degeneration, Science 308(5720) (2005) 419-21.

[50] Z. Yang, N.J. Camp, H. Sun, Z. Tong, D. Gibbs, D.J. Cameron, H. Chen, Y. Zhao, E. Pearson, X. Li, J. Chien, A. Dewan, J. Harmon, P.S. Bernstein, V. Shridhar, N.A. Zabriskie, J. Hoh, K. Howes, K. Zhang, A variant of the HTRA1 gene increases susceptibility to age-related macular degeneration, Science 314(5801) (2006) 992-3.

[51] Y. Tong, J. Liao, Y. Zhang, J. Zhou, H. Zhang, M. Mao, LOC387715/HTRA1 gene polymorphisms and susceptibility to age-related macular degeneration: A HuGE review and meta-analysis, Mol Vis 16 (2010) 1958-81.

[52] Y. Chen, M. Bedell, K. Zhang, Age-related macular degeneration: genetic and environmental factors of disease, Mol Interv 10(5) (2010) 271-81.

[53] G.S. Hageman, D.H. Anderson, L.V. Johnson, L.S. Hancox, A.J. Taiber, L.I. Hardisty, J.L. Hageman, H.A. Stockman, J.D. Borchardt, K.M. Gehrs, R.J. Smith, G. Silvestri, S.R. Russell, C.C. Klaver, I. Barbazetto, S. Chang, L.A. Yannuzzi, G.R. 
Barile, J.C. Merriam, R.T. Smith, A.K. Olsh, J. Bergeron, J. Zernant, J.E. Merriam, B. Gold, M. Dean, R. Allikmets, A common haplotype in the complement regulatory gene factor $\mathrm{H}$ (HF1/CFH) predisposes individuals to age-related macular degeneration, Proc Natl Acad Sci U S A 102(20) (2005) 7227-32.

[54] Y.H. Kim, S. He, S. Kase, M. Kitamura, S.J. Ryan, D.R. Hinton, Regulated secretion of complement factor $\mathrm{H}$ by RPE and its role in RPE migration, Graefes Arch Clin Exp Ophthalmol 247(5) (2009) 651-9.

[55] E. An, S. Sen, S.K. Park, H. Gordish-Dressman, Y. Hathout, Identification of novel substrates for the serine protease HTRA1 in the human RPE secretome, Invest Ophthalmol Vis Sci 51(7) (2010) 3379-86.

[56] E.Y. Chew, T.E. Clemons, E. Agron, R.D. Sperduto, J.P. Sangiovanni, N. Kurinij, M.D. Davis, Long-term effects of vitamins $\mathrm{C}$ and $\mathrm{E}$, beta-carotene, and zinc on agerelated macular degeneration: AREDS report no. 35, Ophthalmology 120(8) (2013) 1604-11 e4.

[57] S. Zeng, J. Hernandez, R.F. Mullins, Effects of antioxidant components of AREDS vitamins and zinc ions on endothelial cell activation: implications for macular degeneration, Invest Ophthalmol Vis Sci 53(2) (2012) 1041-7.

[58] A. Carneiro, J.P. Andrade, Nutritional and Lifestyle Interventions for AgeRelated Macular Degeneration: A Review, Oxid Med Cell Longev 2017 (2017) 6469138.

[59] R. Vishwanathan, M. Chung, E.J. Johnson, A systematic review on zinc for the prevention and treatment of age-related macular degeneration, Invest Ophthalmol Vis Sci 54(6) (2013) 3985-98.

[60] L. Rink, Zinc in Human Health, IOS Press2011.

[61] A. Finamore, M. Massimi, L. Conti Devirgiliis, E. Mengheri, Zinc deficiency induces membrane barrier damage and increases neutrophil transmigration in Caco-2 cells, J Nutr, United States, 2008, pp. 1664-70.

[62] G. Carr, J.A. Wright, N.L. Simmons, Epithelial barrier resistance is increased by the divalent cation zinc in cultured MDCKII epithelial monolayers, J Membr Biol 237(2-3) (2010) 115-23.

[63] X. Wang, M.C. Valenzano, J.M. Mercado, E.P. Zurbach, C.J. Flounders, J.M. Mullin, Zinc enhancement of LLC-PK(1) renal epithelial barrier function, Clin Nutr, 2013 Elsevier Ltd and European Society for Clinical Nutrition and Metabolism, England, 2014, pp. 280-6.

[64] J. Mercado, M.C. Valenzano, C. Jeffers, J. Sedlak, M.K. Cugliari, E. Papanikolaou, J. Clouse, J. Miao, N.E. Wertan, J.M. Mullin, Enhancement of tight junctional barrier function by micronutrients: compound-specific effects on permeability and claudin composition, PLoS One 8(11) (2013) e78775.

[65] M.C. Valenzano, K. DiGuilio, J. Mercado, M. Teter, J. To, B. Ferraro, B. Mixson, I. Manley, V. Baker, B.A. Moore, J. Wertheimer, J.M. Mullin, Remodeling of Tight Junctions and Enhancement of Barrier Integrity of the CACO-2 Intestinal Epithelial Cell Layer by Micronutrients, PLoS One 10(7) (2015) e0133926.

[66] B. Zhang, Y. Guo, Supplemental zinc reduced intestinal permeability by enhancing occludin and zonula occludens protein-1 (ZO-1) expression in weaning piglets, Br J Nutr, England, 2009, pp. 687-93.

[67] Y. Kress, F. Gaskin, C.F. Brosnan, S. Levine, Effects of zinc on the cytoskeletal proteins in the central nervous system of the rat, Brain Res, Netherlands, 1981, pp. $139-49$.

[68] Z. Ablonczy, M. Dahrouj, P.H. Tang, Y. Liu, K. Sambamurti, A.D. Marmorstein, C.E. Crosson, Human retinal pigment epithelium cells as functional models for the 
RPE in vivo, Invest Ophthalmol Vis Sci 52(12) (2011) 8614-20.

[69] J. Hu, D. Bok, Culture of highly differentiated human retinal pigment epithelium for analysis of the polarized uptake, processing, and secretion of retinoids, Methods Mol Biol 652 (2010) 55-73.

[70] U. Schraermeyer, K. Heimann, Current understanding on the role of retinal pigment epithelium and its pigmentation, Pigment Cell Res 12(4) (1999) 219-36.

[71] H.Y. Han, H.C. Zou, J.Y. Jeon, Y.J. Wang, W.A. Xu, J.M. Yang, Y.D. Park, The inhibition kinetics and thermodynamic changes of tyrosinase via the zinc ion, Biochim Biophys Acta, Netherlands, 2007, pp. 822-7.

[72] C. Olivares, F. Solano, New insights into the active site structure and catalytic mechanism of tyrosinase and its related proteins, Pigment Cell Melanoma Res, England, 2009, pp. 750-60.

[73] J.R. Jara, F. Solano, J.C. Garcia-Borron, P. Aroca, J.A. Lozano, Regulation of mammalian melanogenesis. II: The role of metal cations, Biochim Biophys Acta 1035(3) (1990) 276-85.

[74] F. Solano, C. Jimenez-Cervantes, J.H. Martinez-Liarte, J.C. Garcia-Borron, J.R. Jara, J.A. Lozano, Molecular mechanism for catalysis by a new zinc-enzyme, dopachrome tautomerase, Biochem J 313 ( Pt 2) (1996) 447-53.

[75] A. Biesemeier, S. Julien, D. Kokkinou, U. Schraermeyer, O. Eibl, A low zinc diet leads to loss of $\mathrm{Zn}$ in melanosomes of the RPE but not in melanosomes of the choroidal melanocytes, Metallomics 4(4) (2012) 323-32.

[76] S. Julien, A. Biesemeier, D. Kokkinou, O. Eibl, U. Schraermeyer, Zinc deficiency leads to lipofuscin accumulation in the retinal pigment epithelium of pigmented rats, PLoS One 6(12) (2011) e29245.

[77] D. Kokkinou, H.U. Kasper, T. Schwarz, K.U. Bartz-Schmidt, U. Schraermeyer, Zinc uptake and storage: the role of fundus pigmentation, Graefes Arch Clin Exp Ophthalmol 243(10) (2005) 1050-5.

[78] J.G. Hu, R.P. Gallemore, D. Bok, A.Y. Lee, D.A. Frambach, Localization of NaK ATPase on cultured human retinal pigment epithelium, Invest Ophthalmol Vis Sci 35(10) (1994) 3582-8.

[79] G.L. Lehmann, I. Benedicto, N.J. Philp, E. Rodriguez-Boulan, Plasma membrane protein polarity and trafficking in RPE cells: past, present and future, Exp Eye Res 126 (2014) 5-15.

[80] B.Y. Ishida, K.G. Duncan, K.R. Bailey, J.P. Kane, D.M. Schwartz, High density lipoprotein mediated lipid efflux from retinal pigment epithelial cells in culture, $\mathrm{Br} \mathrm{J}$ Ophthalmol 90(5) (2006) 616-20.

[81] E. An, X. Lu, J. Flippin, J.M. Devaney, B. Halligan, E.P. Hoffman, N. Strunnikova, K. Csaky, Y. Hathout, Secreted proteome profiling in human RPE cell cultures derived from donors with age related macular degeneration and age matched healthy donors, J Proteome Res 5(10) (2006) 2599-610.

[82] G.J. McKay, C.C. Patterson, U. Chakravarthy, S. Dasari, C.C. Klaver, J.R. Vingerling, L. Ho, P.T. de Jong, A.E. Fletcher, I.S. Young, J.H. Seland, M. Rahu, G. Soubrane, L. Tomazzoli, F. Topouzis, J. Vioque, A.D. Hingorani, R. Sofat, M. Dean, J. Sawitzke, J.M. Seddon, I. Peter, A.R. Webster, A.T. Moore, J.R. Yates, V. Cipriani, L.G. Fritsche, B.H. Weber, C.N. Keilhauer, A.J. Lotery, S. Ennis, M.L. Klein, P.J. Francis, D. Stambolian, A. Orlin, M.B. Gorin, D.E. Weeks, C.L. Kuo, A. Swaroop, M. Othman, A. Kanda, W. Chen, G.R. Abecasis, A.F. Wright, C. Hayward, P.N. Baird, R.H. Guymer, J. Attia, A. Thakkinstian, G. Silvestri, Evidence of association of APOE with age-related macular degeneration: a pooled analysis of 15 studies, Hum Mutat 32(12) (2011) 1407-16. 
[83] M.G. Pilgrim, I. Lengyel, A. Lanzirotti, M. Newville, S. Fearn, E. Emri, J.C. Knowles, J.D. Messinger, R.W. Read, C. Guidry, C.A. Curcio, Subretinal Pigment Epithelial Deposition of Drusen Components Including Hydroxyapatite in a Primary Cell Culture Model, Invest Ophthalmol Vis Sci 58(2) (2017) 708-719.

[84] M. Miyata, J.D. Smith, Apolipoprotein E allele-specific antioxidant activity and effects on cytotoxicity by oxidative insults and beta-amyloid peptides, Nat Genet 14(1) (1996) 55-61.

[85] H. Xu, V.B. Gupta, I.J. Martins, R.N. Martins, C.J. Fowler, A.I. Bush, D.I. Finkelstein, P.A. Adlard, Zinc affects the proteolytic stability of Apolipoprotein E in an isoform-dependent way, Neurobiology of disease 81 (2015) 38-48.

[86] H. Xu, D.I. Finkelstein, P.A. Adlard, Interactions of metals and Apolipoprotein E in Alzheimer's disease, Front Aging Neurosci 6 (2014) 121.

[87] S.I. Koo, C.C. Lee, Compositional changes in plasma high-density lipoprotein particles in marginally zinc-deficient male rats, Am J Clin Nutr 47(1) (1988) 120-7.

[88] D.H. Anderson, S. Ozaki, M. Nealon, J. Neitz, R.F. Mullins, G.S. Hageman, L.V. Johnson, Local cellular sources of apolipoprotein $\mathrm{E}$ in the human retina and retinal pigmented epithelium: implications for the process of drusen formation, Am $\mathrm{J}$ Ophthalmol, United States, 2001, pp. 767-81.

[89] J.W. Crabb, M. Miyagi, X. Gu, K. Shadrach, K.A. West, H. Sakaguchi, M. Kamei, A. Hasan, L. Yan, M.E. Rayborn, R.G. Salomon, J.G. Hollyfield, Drusen proteome analysis: an approach to the etiology of age-related macular degeneration, Proc Natl Acad Sci U S A 99(23) (2002) 14682-7.

[90] M. Johnson, Fetal bovine serum, 2012. https://www.labome.com/method/FetalBovine-Serum.html.

[91] H. Faure, A. Favier, M. Tripier, J. Arnaud, Determination of the major zinc fractions in human serum by ultrafiltration, Biol Trace Elem Res 24(1) (1990) 25-37.

[92] W.R. Harris, C. Keen, Calculations of the distribution of zinc in a computer model of human serum, J Nutr 119(11) (1989) 1677-82.

[93] J.W. Foote, H.T. Delves, Albumin bound and alpha 2-macroglobulin bound zinc concentrations in the sera of healthy adults, J Clin Pathol 37(9) (1984) 1050-4.

[94] D.J. Tate, Jr., M.V. Miceli, D.A. Newsome, Zinc protects against oxidative damage in cultured human retinal pigment epithelial cells, Free Radic Biol Med, United States, 1999, pp. 704-13.

[95] C.J. Kennedy, P.E. Rakoczy, T.A. Robertson, J.M. Papadimitriou, I.J. Constable, Kinetic studies on phagocytosis and lysosomal digestion of rod outer segments by human retinal pigment epithelial cells in vitro, Exp Cell Res, United States, 1994, pp. 209-14.

[96] H.J. Hyun, J.H. Sohn, D.W. Ha, Y.H. Ahn, J.Y. Koh, Y.H. Yoon, Depletion of intracellular zinc and copper with TPEN results in apoptosis of cultured human retinal pigment epithelial cells, Invest Ophthalmol Vis Sci 42(2) (2001) 460-5.

[97] A.C. Bird, The Bowman lecture. Towards an understanding of age-related macular disease, Eye (Lond) 17(4) (2003) 457-66.

[98] S.J. Zyba, S.V. Shenvi, D.W. Killilea, T.C. Holland, E. Kim, A. Moy, B. Sutherland, V. Gildengorin, M.K. Shigenaga, J.C. King, A moderate increase in dietary zinc reduces DNA strand breaks in leukocytes and alters plasma proteins without changing plasma zinc concentrations, Am J Clin Nutr 105(2) (2017) 343-351. [99] N.K. Wills, V.M. Ramanujam, N. Kalariya, J.R. Lewis, F.J. van Kuijk, Copper and zinc distribution in the human retina: relationship to cadmium accumulation, age, and gender, Exp Eye Res, England, 2008, pp. 80-8.

[100] I. Lengyel, J.M. Flinn, T. Peto, D.H. Linkous, K. Cano, A.C. Bird, A. Lanzirotti, 
C.J. Frederickson, F.J. van Kuijk, High concentration of zinc in sub-retinal pigment epithelial deposits, Exp Eye Res, England, 2007, pp. 772-80.

[101] J.C. Erie, J.A. Good, J.A. Butz, J.S. Pulido, Reduced zinc and copper in the retinal pigment epithelium and choroid in age-related macular degeneration, Am J Ophthalmol, United States, 2009, pp. 276-282 e1. 


\section{FIGURE LEGENDS}

FIGURE 1. Determination of free zinc concentrations in the Miller medium. Free zinc concentration in the Miller medium was determined based on changes of fluorescence intensity ratio as a function of total zinc added. Black circles (•) represent the calculated concentration of free zinc using MINEQL [13]. Open circles ( $\circ$ ) indicate free zinc concentrations measured by emission intensity ratios using a fluorescent biosensor composed of wild type bovine apo-carbonic anhydrase II and polymeric $\mathrm{ABDN}$, and open squares $(\square)$ represent free zinc levels measured using human H94N apo-CA II plus poly-ABDN. Under these conditions the zinc binding KD's of wt bovine and human H94N CA-II's are measured as $0.10 \pm 0.03$ and $0.71 \pm$ $0.06 \mathrm{nM}$, respectively (results not shown). The double logarithmic plot estimated that at $125 \mu \mathrm{M}$ of added zinc the free zinc concentration is approximately $3.4 \mathrm{nM}$ (dashed line).

FIGURE 2. Transepithelial (TER) measurements of the RPE cultures supplemented with $0,75,100,125$, and $150 \mu \mathrm{M}$ zinc. TER measurements of RPE grown with $0 \mu \mathrm{M}(-\bullet-), 75 \mu \mathrm{M}(-\circ-), 100 \mu \mathrm{M}(-\square-), 125 \mu \mathrm{M}(-\mathbf{-}-)$, and $150 \mu \mathrm{M}\left(-\Delta_{-}\right)$ added zinc were measured with an epithelial volt-ohm meter. $100 \mu \mathrm{M}\left({ }^{*}\right)$ and 125 $\mu \mathrm{M}(\#)$ added zinc demonstrated statistically significant $(\mathrm{p}<0.05)$ increases in TER compared to $0 \mu \mathrm{M}$.

FIGURE 3. Effects of added zinc on RPE pigmentation and cell differentiation. RPE cultures developed pigmentation and this was observed under light microscopy (panels A\&D). TEM (B\&E) showed characteristics of RPE cell differentiation including pigment maturation (M) and microvilli (MV) development. IHC images (C\&F) indicated melanosome (green), ApoE (magenta) and nuclei (blue). (G) Zinc concentration dependent increase in pigmentation was analysed by ImageJ and coverage was determined as percentage of total image area of three inserts in each condition; \# labels values that are significantly different from no added zinc $(p<0,05)$. Asterisks indicate Millicell-HA Culture Plate Inserts; scale bar is $10 \mu \mathrm{m}$.

FIGURE S1. Determination of toxicity of added zinc to RPE cultures. Cell culture medium was collected from the apical (A) and basal (B) compartments of the culture 
inserts and assessed by a colorimetric assay. Maximum LDH (dotted lines) was measured by complete lysis of confluent RPE. LDH release was measured after incubating the cells for different length of time with $0 \mu \mathrm{M}(-\bullet-), 75 \mu \mathrm{M}(-\circ-), 100 \mu \mathrm{M}$ (-口-), $125 \mu \mathrm{M}(-\mathbf{m}-)$, and $150 \mu \mathrm{M}(-\Delta-)$ added zinc. 